\title{
CANAL CONFIGURATION IN THE ROOTS OF MAXILLARY SECOND PREMOLAR: A CLINICAL STUDY
}

\author{
M. R. Ganesh.
}

1. Reader, M. D. S. Department of Conservative \& Endodontic, Adiparashakthi Dental College. Melmaruvathur, Chennai.

\section{CORRESPONDING AUTHOR}

Dr. M. R. Ganesh,

C. S. T. Compound at the back of G. P. O,

Mumbai-1, Maharashtra, India,

E-mail: watvrukshpippal909@gmail.com,

Ph: 00918600117037.

ABSTRACT: Modified access cavity preparation and X ray- interpretation were used clinically to find out the additional canals in the root of maxillary second premolars. In $85 \%$ of the case two canals were located and treated, of these $30 \%$ had two separate apical foramen and $50.66 \%$ had two canal, joined at the apical third in $5 \%$ of the cases, two roots with two different canals were located and in $15 \%$ of the cases, one canal was located.

KEY WORDS: Access Preparation, Apical Foramen.

INTRODUCTION: In the modern era of endodontics where clinicians have completely understood the root canal anatomy and configuration. ${ }^{1,2}$, variation in the morphology of the dental pulp is caused by genetic and environmental influences. The canal configuration has clinical as well as biological significance. It is well known fact that root canal microbial flora is most complex. ${ }^{3}$ Very few studies have related to the presence of an additional canal in the maxillary second premolars. The main aim of the present clinical study was to find out the canal configuration in the maxillary second premolars which were undergoing enododontic treatment.

MATERIAL AND METHODS: 100 patients with no age and sex bar were selected for this study. Periapical radiograph of the tooth was well examined. In carious tooth, the caries was excavated with the help of excavator and round bur at slow speed hand piece. Access through the occlusal surface was taken with round diamond point. Access cavity was ovoid in a buccopalatal direction. Then with long tapered diamond point; the initial penetration of the pulp chamber was done towards the axis of the palatal canal. The root of the pulp chamber was completely removed using the cutting action of the bur, only on the withdrawal stroke to avoid the possibility of damage to the floor of the pulp chamber. The pulp chamber was made wide buccopalatally. As the root canal openings lies well below the cervical level and may not be seen easily, the floor of the pulp chamber extended well apically below the cervical level. First palatal canal was located palatally and then the buccal canal was located in the centre of the pulp chamber. Pulp tissue was extirpated and the initial instrumentation was done. With root canal instruments in two canals, X-ray was taken. Due to overlapping of bucfal and palatal canals, radiographs were repeated with different angulation.

Root canals were biomechanically prepared and obturated when they were absolutely dry and the teeth were asymptomatic. 
RESULTS: Out of 100 maxillary second premolars; only 10 premolars had single canal. 5 premolars had type IV canals with two separate roots. 40 premolars had type IV canals and 45 premolars had type II and type III canals.

There was no significant difference in the results on male and female or the left and right sided premolars.

Table showing number of teeth, type of canal and its percentage

\begin{tabular}{|c|c|c|}
\hline No. of teeth & Type of canal & Percentage \\
\hline 45 & II \& III & $50.66 \%$ \\
\hline 40 & IV & $30.00 \%$ \\
\hline 10 & Inhibition & $15 \%$ \\
\hline 5 & IV & $5 \%$ \\
\hline
\end{tabular}

DISCUSSION: Many root possess additional canal and variety of canal configuration. The maxillary second premolar tends to be single rooted tooth. The type I canal form is prevalent; however over $24.5 \%$ of these may present type II and type III canal and further $24.5 \%$ may have type IV and type IV form with two canals at the apex.

In this study, in many teeth, initially only palatal canal was located. Then by extending pulp chamber buccally and more cervically buccal canal was also located. The percentage of type II and type III canals was very high (i.e. $51.66 \%$ ) as compared to type I canal that was only $10 \%$. Percentage of type I canal was very low when compared with standard text book on Endodontics which report 50 to 64\%. Percentage of type IV canal was acceptable $30 \%$ compared to text books where it is reported to be $24.5 \%$. One canal at the apex was also acceptable (60\%) compared to the text books reporting $74.5 \%$. Two roots with two different canals was found in 4.5 which is rarely mentioned in the text books.

In $37.11 \%$ two separate apical foramina were located and in $60.5 \%$ one foramen was located.

CONCLUSION: The root canal system is complex and the canals may divide and rejoin each other and possess different forms which are considerably more involved.

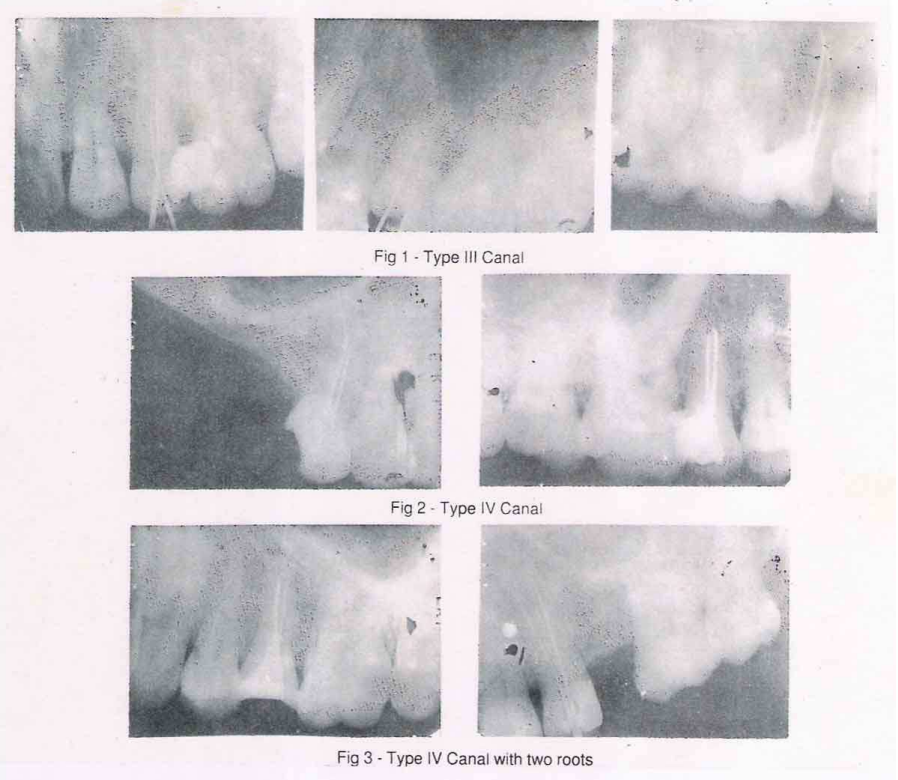

Journal of Evolution of Medical and Dental Sciences/Volume1/ Issue4/October - 2012 Page 599 


\section{REFERENCES:}

1. Siqueira JF, Mechanical reduction of bacterial population in the root canal by in strumentation technique. JOE 1999;25.

2. Siqueira JF, Chemomechanical reduction of the bacterial population in root canal after instrumentation and irrigation with $1 \%, 2.5 \%$ and $5.25 \%$ sodium hypochlorite solution, JOE 2000;26.

3. Sundqvist, Ecology of root canal flora. JOE 1992.

4. Cohen S. Pathways of the pulp. 1980, p. 97.

5. Harty F J. Endodontics in Clinical Practice 1990, p. 35.

6. Fogel H.M. Canal configuration in the mesiobuccal root of the maxillary first molar: J Endod. 1994; 20:135-137.

7. Wein, Basis of successful endodontic therapy, Textbook of endodontics. 